Кокурина И.Г., Юсуфова О.О.

Взаимосвязь ценности доверия с особенностями эмоционального реагирования на слова-стимулы трудовой деятельности у представителей малого бизнеса и наёмного персонала

Московский Государственный Университет имени М.В.Ломоносова

(Россия, Москва)

doi: $10.18411 / \mathrm{sr}-10-02-2021-75$

idsp: sciencerussia-10-02-2021-75

\title{
Аннотация
}

В условиях рыночных отношений между работодателем и наёмным персоналом, а также между бизнес партнёрами в процессе общения в совместной работе возникает необходимость в доверии, важного фактора, составляющего содержание «социального капитала». Ценность доверия в деловых коммуникациях повышают их эффективность, которая определяется не только взаимовыгодным результатом, но и эмоциональной удовлетворённостью, повышает оценку базовых стимулов совместной работы. В нашем исследовании мы попытались ответить на вопросы о необходимой «мере доверия» для эффективной совместной деятельности в разных ролевых позициях человека : 1) когда эта деятельность задана рамками наемного труда и обременена отношениями зависимости от работодателя; или 2) когда она представляет собой относительно более свободную индивидуальную предпринимательскую деятельность, которая существенно в большей мере зависит от решений и действий самого человека. Психологические различия между этими двумя позициями мы искали в области эмоций, эмоционального реагирования на набор слов-стимулов, составляющих тезаурус трудовой деятельности. То есть для нас было важно выяснить: существуют ли отличия в эмоциональной сфере между теми, кто занят индивидуальной частной деятельностью (самозанятые), и теми, кто предпочел занять позицию наемного работника? Для ответа на поставленные вопросы было проведено пилотажное исследование.

Ключевые слова: доверие, доверчивость, недоверчивость, самозанятые, наёмный персонал.

Доверие имеет прямое отношение к экономике успеха и развития всего общества. Во взаимодействии между людьми ценность доверия приоритетна и способствует не только взаимопониманию, но и развитию структуры общественных отношений, обеспечивая эффективную деятельность и стабильность в обществе.

По мнению А.Лэнгле, экзистенциальное значение многих ценностей заключается в том, что они оказывают влияние, стимулируют изменения в человеке, встраиваются в жизненную действительность человека. становятся частью его личности и составляют историю её развития. ( А. Лэнгле, 2017).

Такой ценностью является доверие как основа существования человеческого сообщества. Согласно Т.П. Скрипкиной, доверие может служить базисом как отношений между людьми, так и взаимодействия человека с миром в целом и с самим собой. Наличие доверия создает у человека чувство безопасности и оптимизма, которые являются основанием для построения доверительных отношений с другими людьми. Доверие также облегчает взаимодействие, снижает уровень стресса в отношениях, обеспечивает эмоциональный комфорт (Скрипкина, 2001, с. 95).

Американский философ и политический экономист Ф. Фукуяма связывает доверие и экономический прогресс государства. Он определяет доверие как 
способность людей объединяться вне пределов своей семьи и без помощи государства. Сегодня все более значимым становится человеческий капитал, развитие в человеке способности взаимодействовать друг с другом на благо каждого, его готовность подчинять свои интересы общим интересам дела на основе выработки общих норм и ценностей, а также воспитание в человеке желания достигать согласия при принятии важных решений не любыми средствами, а через достижение консенсуса. (Фукуяма, 2004). Результатом этого становится взаимное доверие, которое по мнению Ф. Фукуямы обладает экономической ценностью. Без доверия человек не сможет существовать. Доверие является основой, которая создает у человека чувство безопасности и обеспечивает эмоциональный комфорт. Но для успешного общения должна существовать определенная «мера доверия». Излишняя доверчивость имеет отрицательные последствия. Доверчивые люди чаще становятся жертвами мошенников и манипуляторов. Возникает вопрос о том, как отличить человека доверяющего от доверчивого и недоверчивого.

Операциональным критерием доверия может служить его характеристика как встречного эквивалентного отношения, в то время как доверчивость этим качеством не обладает. В свое время составлены психологические портреты людей, доверяющих и не доверяющих другим. Доверяющий людям человек описывается как достаточно самостоятельный в своих воззрениях, он обладает разнообразными способами воздействия на людей, однако не использует доверие в качестве оружия влияния. Он обладает высокой степенью развития эмпатии, чувством собственного достоинства и чаще всего удовлетворен от общения с другими людьми. В его поведении практически отсутствует враждебность или отчужденность, он не испытывает чувства одиночества. Иначе выглядит психологический портрет человека не доверяющего людям. Люди с низким доверием практически не способны к самораскрытию, ощущают чувство одиночества и у них понижена адаптивность. Такой человек подозрителен, враждебен, авторитарен, скован, робок, закрыт (Ильин, 2013)

Некоторые авторы описывают доверчивого человека как оптимиста, полагающего, что он способен сам управлять своей судьбой; верящего в то, что он живет в мире, где преобладают добрые люди; его доверие к миру основывается на определенном отношении к миру, а не на жизненном опыте (Куницина, 1991).

Доверчивость является отношением к партнерам как к людям, которые не будут применять полученные данные против доверившихся в силу своих нравственных качеств.

В современной жизни у широких слоев населения сегодня появляются новые возможности для активной экономической деятельности в таком виде малого бизнеса, как самозанятость, что позволяет людям с наибольшей эффективностью использовать свой профессиональный и творческий потенциал. В развивающемся информационном обществе, в социальных сетях для самозанятых появляются новые возможности реализовывать свой предпринимательский дух и свою инициативность для нахождения оптимального и эффективного способа реализации коммерческих интересов.

Отличаются ли люди, принявшие решение заняться индивидуальной частной деятельностью (самозанятые) характером эмоционального реагирования на слова стимулы трудовой деятельности от тех, кто предпочел занять позицию наемного работника? Способствует или препятствует установка на доверие занятиям индивидуальной предпринимательской деятельностью? Для ответа на поставленные вопросы было проведено пилотажное исследование.

\section{Эмпирическое исследование}


В проведённом исследовании мы попытались выяснить особенности эмоционального реагирования на слова-стимулы в совместной деятельности у представителей малого бизнеса и наёмного персонала с высокой и низкой установкой на доверие.

Выборка состояла из 102 человек. Среди них мужчин 33 человека и женщин 69 человек. По возрасту респондентов объединили в группы от 17 до 24 лет-66 человек, от 25 до 44 лет- 25 человек и от 45 лет до 65 лет -11 человек. Представителями малого бизнеса являлись самозанятые, а именно физические лища, самостоятельно осуществляющее на свой риск основанную на личном трудовом участии деятельность по оказанию услуг, выполнению работ для физических лиц, направленных на систематическое получение прибыли, не зарегистрированные в качестве индивидуального предпринимателя, не имеющих наёмных работников. (косметологи, парикмахеры, мастера ногтевого сервиса, массажисты и т. д)

Наёмные работники в нашем исследовании являлись студенты, получающие образование и имеющие подработку в сфере обслуживания ( продавцы-консультанты, репетиторы, агенты в сфере недвижимости, официанты, няни).

C помощью опросника ТЭММО (автор А.Лэнгле ,адаптация Уколова Е.M , Шумский В.Б) для измерения установки на доверие у респондентов были выделены три группы по доверию : низко доверяющие (недоверчивые), средне доверяющие (норма) и высоко доверяющие (доверчивые) . Методом семантического дифференциала Ч.Осгуда (СД), модифицированным нами для оценки доверия на данной выборке (Социальная психология, практикум 2006 г.) исследовались эмоциональные реакции на 9 слов-стимулов (ценностей) Доверие, Контроль, Управление, Авторитет, Бизнес, Любовь, Работа, Закон. С помощью этого метода мы оценивали как общую суммарную эмоциональную оценку слов -стимулов по всем шкалам СД, так и эмоциональную оценку каждого слова-стимула по всем шкалам СД. Для обработки полученных результатов использовались программа SPSS Statistics 17.1, описательные статистики (средние значения), тест Колмогорова-Смирнова на нормальность распределения, параметрические критерии (однофакторный дисперсионный анализ AHOBА, Т-тест сравнения средних) , непараметрические (коэффициент корреляции Спирмена, критерии Краскела-Уоллиса, Манна-Уитни).

В группах самозанятых и наемных работников, мы получили любопытную картину эмоционального восприятия набора слов-понятий, составляющих ценностные аспекты в любой трудовой деятельности. Этот набор был создан эмпирическим путем на основе специальной литературы и на основании собственного опыта. По нашему мнению, этот набор слов-стимулов отражает важную часть тезауруса совместной трудовой деятельности людей, живущих в России, в современном мегаполисе в данный исторический период развития мирового экономического кризиса.

\section{Описание результатов}

1.Статистически значимые различия в области эмоционального реагирования в трёх изучаемых группах по доверию были получены на три слова-стимула: Доверие, Любовь, Деньги. Результаты эмоциональных реакций на весь список предложенного набора слов-стимулов (от максимально позитивных к максимально негативным) выстроились в иерархию следующим образом. (таблица№1). В сравниваемых группах за исключением одной (с низкой установкой на доверие) самое высокое эмоциональной значение получило слово-стимул Любовь, а самое низкое и отрицательное значение в сравниваемых группах получило слово-стимул Закон. Иерархия слов-стимулов на основе средних значений по всей выборке выстроилась следующим образом: Любовь (+1.68), Авторитет $(+1.21)$, Доверие $(+0,93)$, Деньги (+0.93), Работа (+0.84), Бизнес $(+0.36)$, Управление $(+0.06)$, Контроль 
(+0.05), Закон (-0.92). Данный результат отражает на общей выборке состояние общественного сознания опрошенной нами группы людей, отражает традиции нигилизма в отношении к законодательной деятельности, к существующим формам Контроля и Управления со стороны государства в области трудовой деятельности

Таблица 1.

Эмочиональная реакция на слова-стимуль Доверие, Любовь, Деньги и установка на доверие

\begin{tabular}{|c|c|c|c|c|c|}
\hline \multicolumn{2}{|c|}{$\begin{array}{c}\text { Низкая группа по } \\
\text { доверию }\end{array}$} & \multicolumn{2}{c|}{ Средняя группа по доверию } & \multicolumn{2}{c|}{ Высокая группа по доверию } \\
\hline Авторитет & 1,15 & Любовь & 2,02 & Любовь & 1,82 \\
\hline Любовь & 1,12 & Деньги & 1,36 & Авторитет & 1,39 \\
\hline Работа & 0,80 & Доверие & 1,30 & Доверие & 1,01 \\
\hline Деньги & 0,65 & Авторитет & 1,12 & Работа & 0,71 \\
\hline Доверие & 0,39 & Работа & 0,96 & Деньги & 0,67 \\
\hline Управление & 0,05 & Бизнес & 0,48 & Бизнес & 0,55 \\
\hline Бизнес & 0,02 & Контроль & $-0,03$ & Управление & 0,37 \\
\hline Контроль & 0,01 & Управление & $-0,18$ & Контроль & 0,21 \\
\hline Закон & $-0,86$ & Закон & $-0,98$ & Закон & $-0,89$ \\
\hline
\end{tabular}

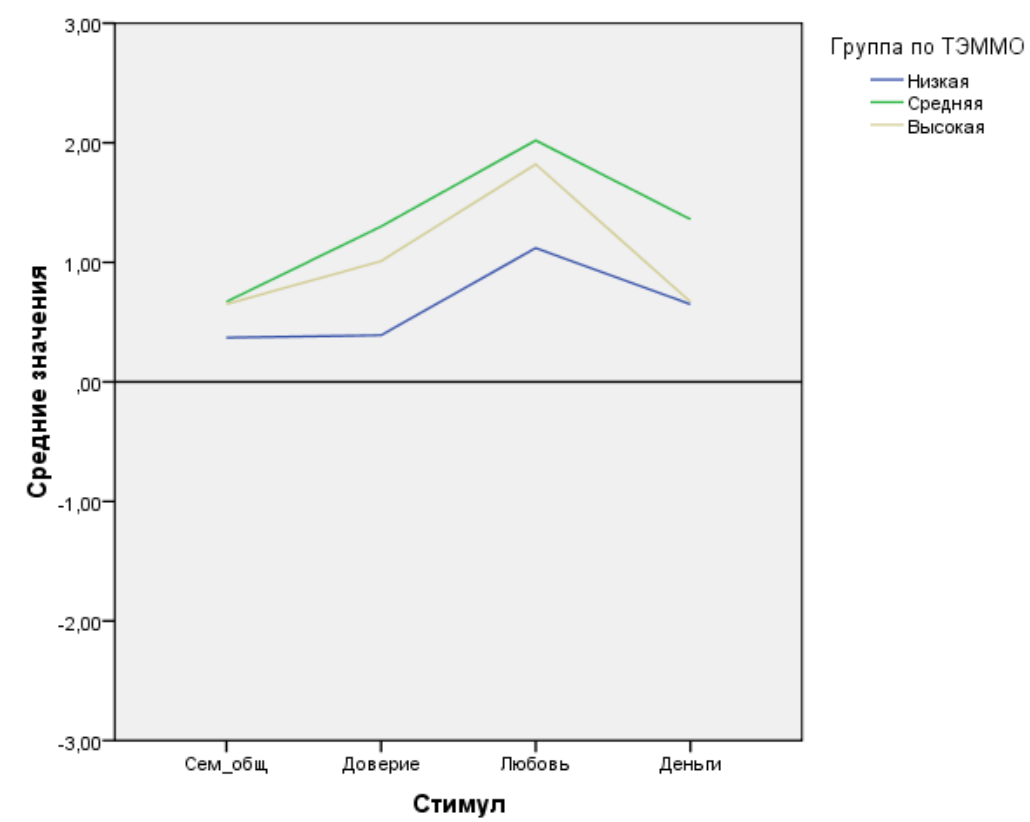

Рис.1 Усреднённые результаты семантического дифференцииала для трех групп респондентов, разделенных по выраженности установки на доверие (низкая, средняя и высокая группы).

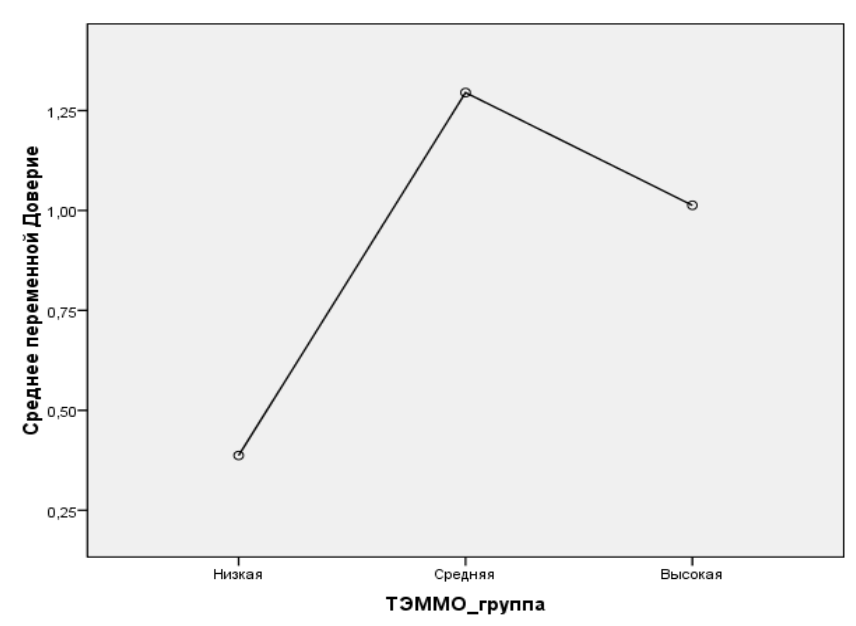

Рис. 2 Эмоциональная реакц̧ия на слово Доверие 


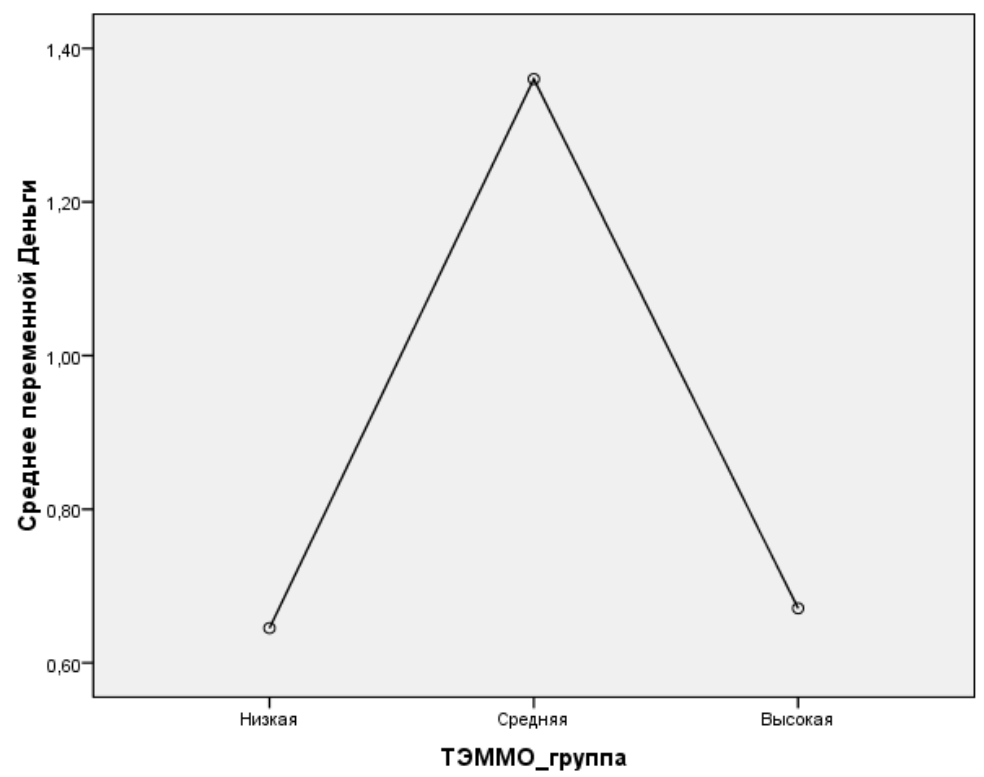

Рис 3 Эмоичиональная реакция на слово Деньги

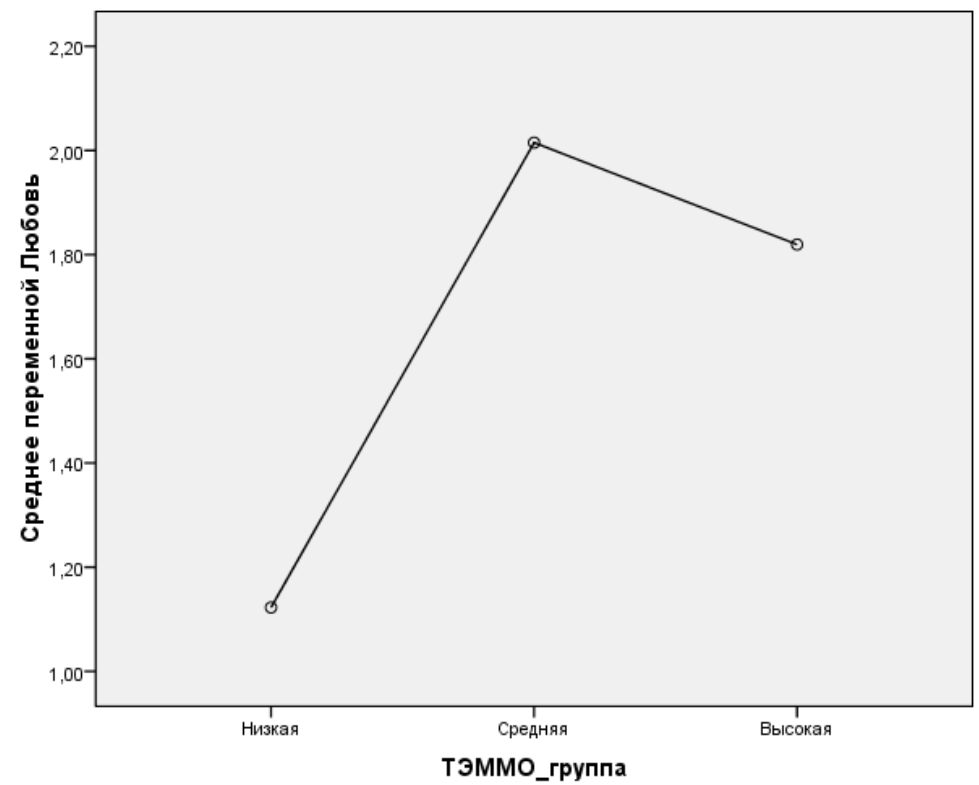

Рис. 4 Эмоциональная реакц̧ия на слово Любовь

Эмоциональные реакции на стимул Деньги (Рис.3) у недоверчивых и доверчивых неожиданно оказались похожими друг на друга, эти реакции оказались крайне низкими в обеих группах по сравнению со средней группой по доверию. Этот результат нельзя объяснить возрастом и полом, он связан с установкой на доверие. И доверчивые и недоверчивые, по-видимому, крайне низко оценивают эту важную социальную ценность, что может служить для них препятствием для занятий предпринимательством. Возможно, отрицательный опыт обращения с деньгами и страх их потерять не способствует, а препятствует занятиям предпринимательской деятельности тем людям, кто излишне доверчив и кто, наоборот, недоверчив. Таким образом, эмоциональное отношение к Деньгам поляризует установку на доверие, снижая и обесценивая их эмоциональную привлекательность у тех кто наоборот недоверчив. Этот результат может служить одним из диагностически значимых показателей в прогнозе успешности или неуспешности в занятиях предпринимательской деятельностью. 
Эмоционально низкая реакция на слово-стимул Любовь (Рис 4) отличает группу недоверчивых от остальных двух групп: с высоким и средним уровнем доверия. Этот результат подтверждает, что именно сфера эмоциональных отношений с самыми близкими людьми является базовым источником формирования Доверия в целом в жизни человека, в его дальнейшей совместной с другими людьми трудовой деятельности. Данный результат подтверждает аксиомы психоанализа о значимости формирования близких межличностных отношений между людьми в жизнедеятельности человека.

Для двух крайних групп: недоверчивых и излишне доверчивых был получен еще один интересный результат, связанный с эмоциональной реакцией на словостимул Авторитет. Эти две группы дали самые высокие эмоциональные реакции на слово-стимул Авторитет по сравнению с группой нормы хотя реакция на это слово и не достигла уровня статистической значимости различий. Этот результат косвенно объясняет эмоционально сниженную оценку стимула Деньги у недоверчивых и доверчивых. Он подтверждает наше предположение, что снижение эмоциональной оценки стимула Деньги приводит как недоверчивых так и доверчивых под защиту Авторитетных лиц или авторитетных социальных структур в обществе. Это защитная реакция тех, для кого Деньги это всегда «зона риска и опасности». Снижение эмоциональной оценки стимула Деньги у недоверчивых и доверчивых тем не менее имеет несколько разное обоснование. В таблице №1 показано, что у доверчивых в иерархии слов-стимулов самую высокую эмоциональную оценку получило словостимул Любовь, а слово-стимул Авторитет занимает лишь второе место по эмоциональной значимости. У недоверчивых в иерархии эмоциональных реакций на первом месте оказалось не слово-стимул Любовь, как у остальных групп, но словостимул Авторитет. По-видимому недоверчивые связывают значение денег с ценностью Власти, властных структур общества прежде всего, а излишне доверчивые связывают значение денег с Любовью к лицам, обладающим Авторитетом в обществе. И те и другие не придают стимулу Деньги автономной силы и значения как независимой и самостоятельной социальной-экономической категории и ценности.

2.Группу самозанятых статистически значимо отличает от группы наемных более позитивная эмоциональная реакция на такие слова-стимулы как: Любовь, Деньги, Работа, Доверие, ( Рис.5, рис.6, рис.7, рис.8)

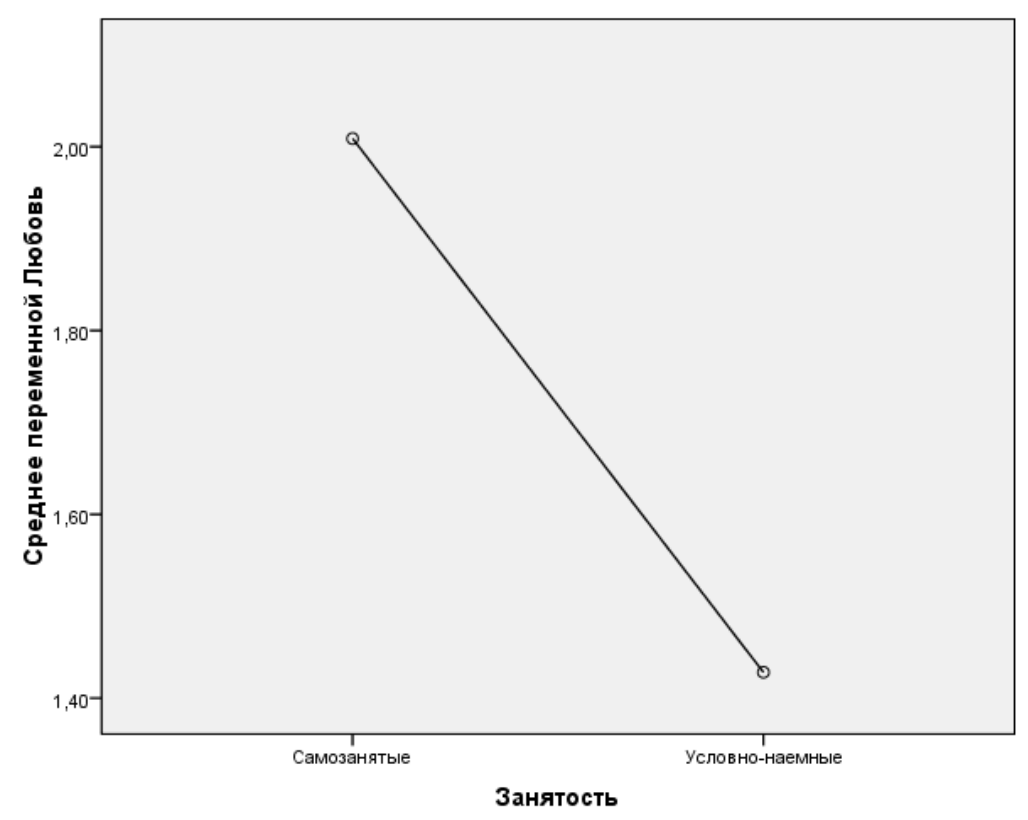

Рис. 5 Эмоциональная реакцุия на слово-стимул Любовь и занятость 


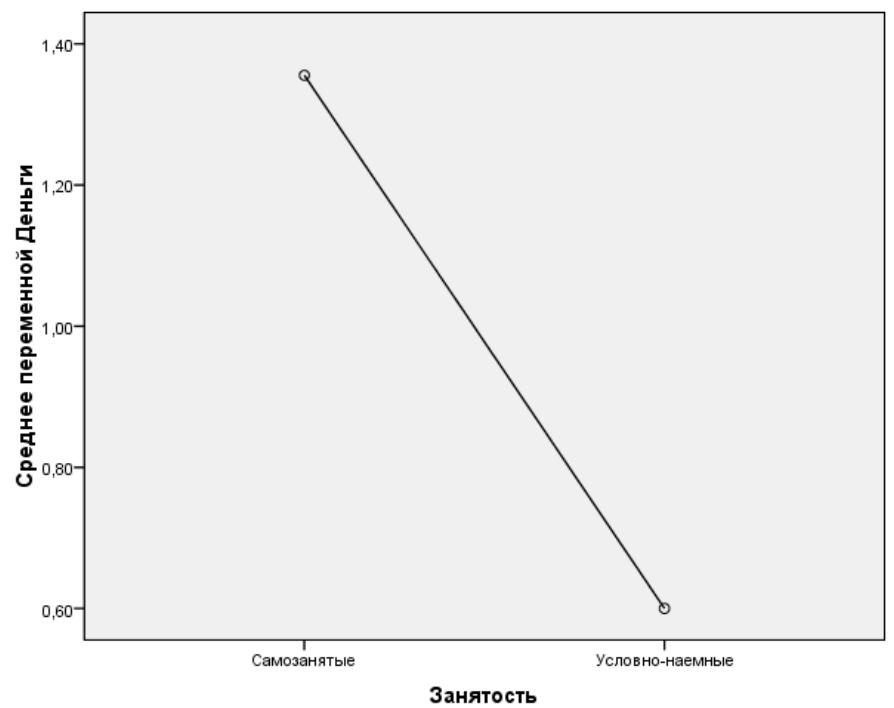

Рис. 6 Эмоциональная реакция на слово-стимул Деньги и занятость

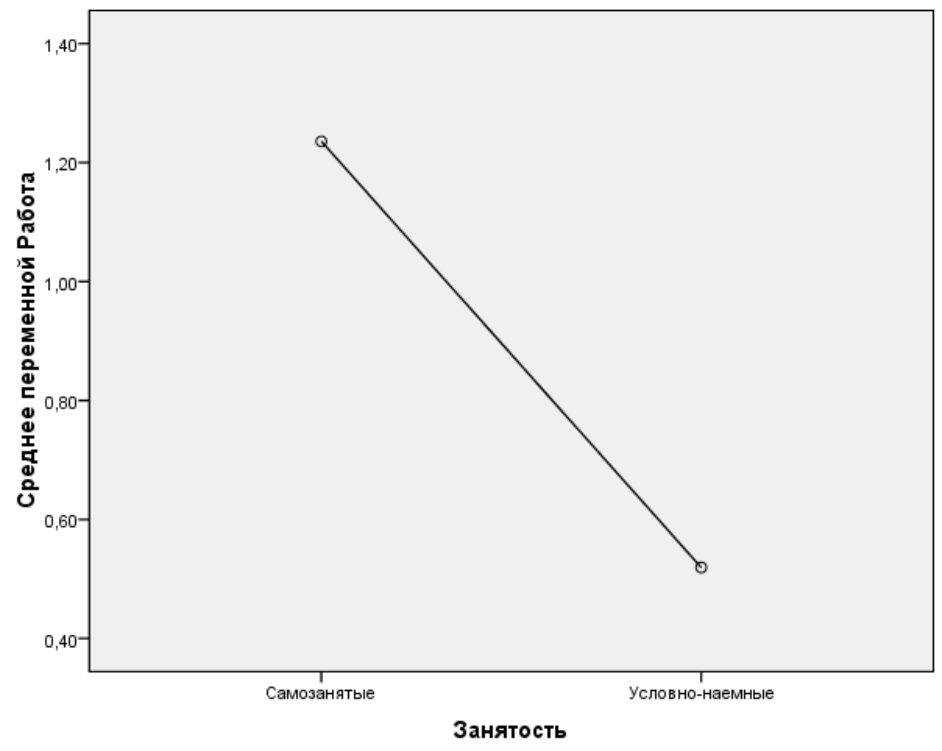

Рис. 7 Эмоциональная реакция на слово-стимул Работа и занятость

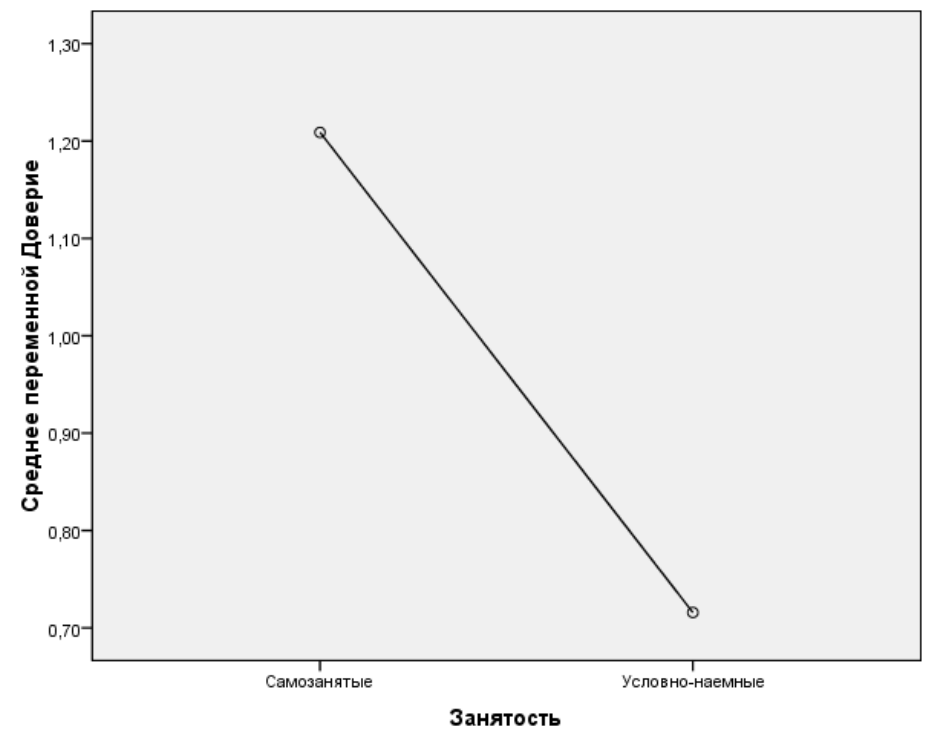

Рис. 8 Эмоциональная реакция на слово-стимул Доверие и занятость 


\section{Bblводы:}

1. Предложенный подход показал, что эмоциональное реагирование на слова-стимулы, отражающие тезаурус понятий в области трудовой деятельности, достаточно чутко и статистически значимо различает людей с разной мерой доверия к другим людям, а также различает людей предпочитающих разные ролевые позиции в трудовой деятельности: быть самозанятым или наёмным работником.

2. Результаты исследования показали прогностические возможности предложенного нами подхода для более успешного выбора человека: кем ему лучше быть-наёмным исполнителем или самозанятым

$$
* * *
$$

1. Ильин Е.П. Психология доверия. - СПб.:Питер,2013

2. Куницина Н.В. Трудности межличностного общения, Дисс.Доктор.психол.наук, СПГУ, 1991

3. Лэнгле А.А. Современный экзистенциальный анализ: история, теория, практика, исследования:монография/А.А.Лэнгле, Е.М Уколова, В.Б. Шумский-М.:Издательство Юрайт, 2018-403 с

4. Скрипкина Т.П Психология доверия. М., 2000

5. Фукуяма Ф. Доверие, социальные добродетели и путь к процветанию / Пер. с англ. М..: АСТ; Ермак, 2004.

6. Юсуфова О.О. Особенности установки на доверие у представителей малого бизнеса и наёмного персонала, Магистерская диссертация, МГУ им. М.В .Ломоносова, Москва, 189 с., 5.06 .2019 г

\section{Поджидаев А.А. \\ Психологический стресс в период пандемической угрозы}

Российский Государственный Педагогический Университет (Россия, Санкт-Петербург)

doi: $10.18411 / s r-10-02-2021-76$

idsp: sciencerussia-10-02-2021-76

\section{Аннотация}

В докладе представлен взгляд на психологическое здоровье индивида в период воздействия на него стрессогенных факторов пандемической угрозы, описаны возможные аспекты, приводящие человека к стрессовому состоянию. Кратко описаны результаты исследования воздействия изменившихся условий социализации на индивида. Описание трудностей обрушившихся на человечество в виде пандемии COVID-19 и дезадаптация психических процессов индивида, в этой связи.

Ключевые слова: психологическое здоровье, стресс, пандемия, COVID-19, самоизоляция, социальное дистанцирование.

Анализируя статьи и монографии о процессах связанных с пандемической угрозой в обществе, можно сделать предположение, что в мировых средствах массовой информации, идёт освещение опасности пандемии, проявленной лишь на физическом уровне, но мало кто освещает психические процессы, происходящие в народных массах. Количество людей пострадавших от пандемии, гораздо больше общеизвестных цифр заражённых. Психологическая дестабилизация затрагивает гораздо большую часть населения, нежели мы имеем количество инфицированных людей на планете. Психологические процессы, происходящие в обществе, связанные с пандемической угрозой, как правило, подвержены трансформационному процессу вследствие изменений норм и правил в обществе, за достаточно короткий период. Ни для кого не секрет, что угроза пандемии застала большинство населения планеты, врасплох. К большинству ограничительных норм, введённых как необходимость защиты от распространения инфекции COVID-19, психика людей не была готова. Такие меры как самоизоляция, социальное дистанцирование н, изменение формата делового и 